\title{
Genre Specificity of S. I. Taneyev's "Oresteia" Trilogy
}

\author{
Galima Lukina \\ State Institiute of Art Studies \\ Russian State Specialized Arts Academy \\ Moscow, Russia \\ E-mail: galimalukina@yandex.ru
}

\begin{abstract}
The article reveals the originality of Sergei Taneyev's approach to tragedy. S. Taneyev treats opera as an oratorical performance with the features of mystery. The author of the article shows the organic fitting of an oratorical component with both the choral component of the Aeschylus' source work and a monumental cantata-like style of the Russian opera and Russian choral culture in S. Taneyev's "Oresteia".
\end{abstract}

Keywords-history of music; genre; Russian opera; S. I. Taneyev; tragedy

\section{INTRODUCTION}

It is considered that in "Oresteia" S.I. Taneyev bases upon the tradition of lyrical musical tragedies of C.W. Gluck, primarily because the opera has "the mythical story, strongly related to the Antique treatment of the myth; exalted ethical issues; impersonal forces and ideas, personified in the characters (each character is the embodiment of one idea, that doesn't preclude, however, the internal struggle, contradiction); general monumental and austere tone" [12. P. $175]$.

On that premise, the musicologists derive Taneyev's attraction towards classicism [Cf. 5. 13. 14. 18]. The aforementioned attributes, however, are too generalized to comprehend the Taneyev's distinct approach to tragedy and reflect thus the narrative and stylistic universality rather than the author-specific interpretation.

\section{SYNTHESIS OF OPERA, ORATORIO AND TRAGEDY}

The Russian musician recognizes an ancient myth, underlying the tragedy, as a universal value for the ages, an expression of high aspirations, which inexhaustible content influences the feelings of people regardless their ethnicity. So there is no contradiction between Taneyev's desire to create the national music and his appeal to Greek tragedy for composing the opera. Tragedy, for Taneyev, has a way of appealing to the inner world of a person with intent to tuning it to a spiritual sobriety through moral purification, which is known as "catharsis" since the ages of Aristotle.

"Oresteia" by Aeschylus, for Taneyev, was a classic example of tragedy as a genre, from which a dramatized tragedy such as "opera seria" was derived. The opera's source designated the absence of the external stage effects, theatrical illustrations, nation-specific story, characters, viewed from the modern-day musical drama's perspective. Many composer's peers viewed that as obvious shortcomings. Yet, those "flaws" belong to the most important properties of tragedy, as indicated by Aristotle in his "Poetics".

While creating the opera, Taneyev sought to move away from the realism of modern theater's musical drama, thus eluding the course, taken by the opera poetics of the $19^{\text {th }}$ century; according to M.G. Aranovskiy, "The struggle for truth to nature led to the personalization of narrative plots, to the description of diverse human destinies and kinds" [1. P. 16]. Individuality interested Taneyev as a manifestation of the universal, choral origin. Like the Ancient Greek tragedians, he made "the general significance and necessity of moral substance, while an individual and subjective depth of the acting characters remains undeveloped within itself" (Hegel) [9. P. 521] the basis of his tragedy.

Taneyev, perceiving the tragedy by Aeschylus as a classic example of the genre, also internalizes its inherent oratorio. The constant sound of chorus both in Taneyev's trilogy and Aeschylus' tragedy allows the audience to participate constantly in the events, taking place in the house of Atreus.

Taneyev demands chorus, unlike R. Wagner, who believed that "the chorus of the Greek tragedy passes its role in the drama to the modern orchestra, in order to reach an infinite variety of forms, developing freely in the said drama ..." [7. P. 642] and that cantata and oratorio genres had outlived their time and had no prospects in the modern art [6. P. 15]. Taneyev thought of opera as chorus, just like M. Glinka, A. Borodin, and N. Rimsky-Korsakov. The chorus' leading role is noticeable in the dominance of the choral and ensemble scenes over the solo ones. In Taneyev's "Oresteia" the chorus of people is almost constantly present, as in Glinka's "A Life for the Tsar", operas by $M$. Mussorgsky, Rimsky-Korsakov. In Taneyev's trilogy, the chorus emerges as a hero, playing the role of people, sympathizing with the characters, their own plight, and future of the motherland. People praise the king, sing a song of praise (\#6 "Glory to the immortal, glory!"), laments for the deceased kings, mourning him (\#16, "Pour thy tears, sobbing for the departed ruler"), cry Orestes for help (\#10, 
"Oh, Orestes, in your salvation; waiting for you to come, to come!"), sympathizes with him, etc. There are only four solo scenes in the whole opera: the monolog of a guard (\#1), the narrative of Aegisthus (\#4), recitative and arioso of Clytaemnestra (\#11) and the scene of Orestes the Wanderer by the tombstone hill (\#14).

In addition to the quantitative predominance of the choral scenes, Taneyev uses the repetition of general and particular motives that serve as the expression of collective feelings. For example, intonation in the first scene, describing the guard's sense of joy on Agamemnon's victory over Troy (\#1) is being picked up by a thankful chorus of slaves and Clytaemnestra (\#2) and the chorus of people, celebrating the great Zeus (\#3). Then, march with chorus (\#5), praising the deeds of the valiant king, is being echoed by Agamemnon and chorus (\#6) in honor of immortal gods. Hymnal and testimonial themes, with all due of the intonation variety, are combined with a general major flair and reliance on the circle of fifths rhythmically active motives. Such a technique creates an overall scenic atmosphere of a patriotic pathos that has gripped the nation.

The immensity of the score, emphasized by the principle of the narrative arcs, is inherent to "Oresteia" as the opera of oratorio type. The first arc is comprised of the orchestral introduction and entracte of the first scene of the third part (\#23). The second arc is formed by the choral scenes of the first tableau of the first part (\#2, "Glory to Zeus Cronion", \#3, "Passing the message from Ides, blazed Athos") and \#26, entr'acte and chorus of Athenians "Goddess-given us a new law" from the third tableau of the third part "The Eumenides". The third arc is comprised of march with chorus "Moment of joy! Desired moment! The heart is boiling with joy!" (\#5) from the second tableau of the first part "Agamemnon" and the concluding scene with Athena (\#30). Wherein the instrumental arc relies on the motive of doom, the choral arc rests upon the praise (of mighty Zeus, the immortal gods, King Agamemnon, wise Athena). Thus, the idea of overcoming doom and achieving peace and harmony is reflected on the narrative level.

Many researchers note [Cf. 12. 20. 21] the genre convergence of Taneyev's trilogy with oratorio. Yet, it is not entirely clear what are the origins of the oratorio in that opera.

In our opinion, oratorio component of Taneyev's "Oresteia" organically blends with both the choral component of Aeschylus' original text and the monumental cantata and oratorio style of the Russian opera, the Russian choral culture at large. Besides, the choral composition of Taneyev's opera experienced the influence of G. Händel's oratorio heritage. At the time of "Oresteia" creation Taneyev, who was studying for many years the choral traditions of European and Russian music, no doubt, mastered the oratorio laws. Apparently, he attributed the form of oratorio, as well as the forms of polyphony, to be "eternal", i.e. "to be independent of any conditions", able "to enter the scope of any harmonic system, to cover all melodic content" [19. P. 89]. In his "Oresteia" Taneyev showcases such "entrance" of oratorio into the genre of tragic opera.
Opera, oratorio and tragedy are entwined in "Oresteia". Because of the said synthesis, there occurs the transformation of opera to the synthetic act of the oratorio type.

\section{MYSTERY PlAY OF THE OPERA}

The peculiarity of the aforementioned synthesis is that oratorio in opera doesn't constitute a waiver of drama in favor of epic (as in Glinka's "Ruslan and Lyudmila" or Borodin's "Prince Igor"). Taneyev considers his trilogy to be namely a tragedy and not a dramatized epic. The most important distinguishing feature of tragedy, as stated by Aristotle, is that it "has a vitality in reading as well as in the action development ... while being a relatively small in volume" [2. P. 735], i.e. tragedy is different from epic by the "effect of its art" [Ibid. P. 736]. Taneyev perceived the special quality inherent to the Aeschylus' tragedy - its action may cause the recipients to feel fine uniting empathy, to beget "an event, internally defining them, perhaps, forever" [11. P. 212]. Chorus allows the audience to feel empathy - it supports the identification of the audience with the character.

One of the most powerful scenes from the perspective of mystery play is the Cassandra scene with the chorus from the first part of the trilogy ("Agamemnon"). The scene's emotional tension is compared to the hallucinatory scene of Tsar Boris in Mussorgsky's opera. Due to the dominance of the motive of doom, there emerges an atmosphere of tension, all-encompassing dread, feeling of the constant presence of the dark forces. For the first time this atmosphere seizes the tragedy witnesses when the seeress envisages the specters of the dead children: "In blood, resentment for a murdered child" (ц. 96). In this scene altos sound menacing, bassoons, and trombones sound diverging move from sixth to tenth. Further on, in Adagio section, there is a motive of impending doom born in the sound of choral basses in the background of crescendo tremolo of the strings and percussions (ц. 98). The injection of drama reaches its climax after a brief lyrical digression - Arioso of Cassandra. Chorus not only comments on the mental state and words of the seeress but cares about her, asks fearfully, increases the excitement.

In the Cassandra scene with the chorus, Taneyev succeeds to achieve a combination of the narrative component, by which the viewers learn the further course of events, and the dramatic component, contributing to the growth of suspense of the internal action of the tragedy. Exactly this internal buildup allows the viewer not to remain a "passive-aesthetic contemplator, as disallows an actor to remain just a play actor" (S. Bulgakov on the staging of F. Dostoevsky's "Demons") [4. P. 8].

In order to enhance "Oresteia's" internal action, Taneyev uses elements, inherent to tragedies and allowing for hard "breaking" action. These are the slowly-paced narrative, introduction of long, fairly independent scenes (e.g., a threepart composition of Cassandra scene with chorus (\#8)), "stop action" method, method of multiple, dispersed repeat of the themes, carrying the ideas, etc.

There is a letter to P. Tchaikovsky in which Taneyev comments on the specifics of time interpretation in his 
trilogy, noting "an unusually long stay of the same person on stage, almost non-existent in contemporary drama plays" [3. P. 49]. He further explains: "This shall not be attributed to the libretto shortcomings. This is a feature common to all the ancient tragedies" [Ibid. P. 141]. Taneyev felt the fundamental difference between the theory of the three classical unities and the perception of time as a particular case of eternity, inherited by the tragedies from the mystery plays.

Special tension, experienced by the audience, is achieved, paradoxically, by the "stop action" method [3. P. 49]. The most indicative example is a dialogue of Clytaemnestra with the slave (scene \#20, ц. 214), following the death of Aegisthus. Injection of interrogative intonations into the part of Clytaemnestra ("What mean these cries?") and into the part of the slave ("The living killed by dead!") is being replaced by "stop"-a shrill sound of a B trumpet (author's mark - "Clytaemnestra stares at the slave").

The "stop action" method is found in the Russian opera. Let us recall: the canon of oblivion in the first act of "Ruslan and Lyudmila", "ensemble of premonition" ("I am frightened!") in the first act of "The Queen of Spades", silence at the meeting of Marfa with the tsar in "The Tsar's Bride". The static scene performs in "Oresteia" the function of a kind of a trigger, shifting action from the world of ideas into the world of ongoing intentions, drawing the conflict from the "hidden" stage into the open. Such scenes are inherent to tragedy. Aristotle in his "Poetics" counts them to "recognition", to the moment in the plot, when "a change from ignorance to knowledge" occurs. Indeed, before the aforementioned scene, the conflict of Clytaemnestra and Orestes was in "invisible" phase, but during the said scene Clytaemnestra unexpectedly discovers the real meaning of the recent events. The same dramatic method, i.e., toggling invisible action plans visible, is carried by the scene of Clytaemnestra with Aegisthus (ц. 41, "Appease the summons of the dead, the wrath of friends on earth"), where it's used before the Queen's recognition of her willingness to kill Agamemnon; the second example is the "silent" scene of Cassandra (E ostinato contra octave in ц. 82 after the line "O thou Apollo, thou Destroyer named! What way hast led me, to what evil home?"), which precedes the disclosure of the true events taking place in the House of Atreus by the seeress.

As a mean of overcoming the static scenes, inherent to large-scale choral scenes, Taneyev, like Glinka and Borodin, uses the method of contrast. This refers to the contrast change of images, musical themes, and events. The Contrast in "Oresteia" is implemented through the opposition of lines of actions and counteractions. Accruing of semantic, figurative comparisons contributes to the growth of the dramatic tension, culminating in the scenes of the heroes' death (first Agamemnon, Cassandra, then Clytaemnestra and Aegisthus). The contrast creates a two-pronged action, wherein the conflict in "Agamemnon" stays hidden. The same contrast is found in "The Libation-Bearers", where the quartet of Clytaemnestra, Electra, Orestes and Aegisthus ("Give them such guest-right as beseems our halls") introduces light sound in the overall gloomy atmosphere, creating a falsely warm and welcoming "aura" for the guest
(Orestes) meeting in the House of Atreus. However, the premonitory chain of events allows the viewer to "read" the quartet's hidden meaning. In its further development, a double canon, which content is associated with the announcement of the alleged death of Orestes, ensemble is divided into two hostile pairs. Clytaemnestra and Aegisthus cease to conceal their joy ("Whate'er thy news, thou shalt not welcome lack, meet and deserved, nor scant our grace shall be"), while Orestes and Electra, noting that "she [Clytaemnestra] is encouraged by the death of her son", come to understanding - Not vain this dream - it bodes a man's revenge".

The action in the quartet (as in the scenes of Agamemnon meeting Clytaemnestra (\#7) and the duet of Clytaemnestra and Electra with chorus (\#13)) is divided into two distinct, unmatching planes. The first, action plane is a scenic "surface", almost never expressing anything important in terms of internal problems, struggles, conflicts. This is a plane, documenting the outer layer of character's behavior, interaction. The second, internal plane is read as the subtext, revealing the essence of the "game" that precede the death of the characters. Thus, the internal plane facilitates the escalation of the "Oresteia's" dramatic tension, when the internal struggle of the characters is as important as the events, taking place on stage.

The images of Clytaemnestra and Orestes differ starkly in their internal psychic structure, that is expressed through the trilogy's musical drama, which is clearly dominated by the two contrasting lines. The first line is associated with the development of Clytaemnestra's image, whose selfish, lustful, prideful soul impedes her spiritual formation, leads to a cessation of a bond between her soul and spirit. The development of the Orestes' dramatic line is based on the logic of "spiritual man" formation, capable of moral suffering, sins overcoming, warning and confronting evil.

Thus, Taneyev's trilogy reinvents the inherent to myth epic motive of the predestination of life and deeds of a character, his dependence on the immutable laws of existence. The world in "Oresteia" is perceived inseparable from human actions. Orestes takes Apollo's command as a conscious personal will. Within this lies the similarity with the Aeschylus' version of the myth of Orestes. Yet, if Aeschylus uses the means of overcoming the epic worldview and identifying "the tragic contradictions ... inherent to the universe" [22. P. 289], Taneyev's perception of the world is in line with the Christian anthropology, according to which the world is divine creation, created for man and to be perfected by man. An individual is always in need of gradual spiritual growth and has a "permanent possibility for accretion and improvement" [8. P. 140]. Naturally, Taneyev chooses Aeschylus' tragedy, in which during the "continuous flow of events ... occurs a change from misery to happiness" [2. P. 708]. This is the essential difference of "Oresteia" from any other tragedies with a fatal ending. It is instructive to recall, that Mussorgsky chooses for his operas the tragedy with the other plot-"from happiness to misery", thereby affirming the idea of death at the level of plot. The meaning of Taneyev's "Oresteia" is, by contrast, in the strengthening the hope and faith in eternal life. Orestes, completing his 
tragic way, experiences in the scene of forgiveness a truly Christian sense of heavenly joy, while realizing the great price of salvation. Taneyev treats the concluding scene in accordance with the Christian idea of soul salvation through repentance. It is not about saving the character's life in the earthly world (as in the so-called "happy ending" finales), not about saving the individual self, but about the enlightenment of the soul, seeking salvation in the eternal world, by which the universal happiness and bliss become possible. Taneyev renders the catharsis, occurring in the tragedy, in the Christian way.

"Oresteia" lacks the tragic conflict insolubility, the tragic death of the protagonist. Taneyev strengthens the "nontragical" end of the myth in his interpretation of Aeschylus' tragedy. The lightness of the ideals of love, compassion, mercy distinguishes the way of Taneyev's Orestes from the Aeschylus' one. Although, of course, the very idea of the way, that was transferred into the tragedy from the Eleusinian Mysteries, initiation into which taught the Greeks, according to Cicero, "to be happy not only in this life but to die with a hope for the better" [Cited by 15. P. 7-8], shows the pre-Christian culture's quest for the divine matter.

\section{CONCLUSION}

S. Taneyev reviews in his "Oresteia" formed in the $19^{\text {th }}$ century form of opera, suggesting to abandon a theatrical tragedy in the form of "opera seria". Apparently, he, like S. Bulgakov, understood that "the world will not be saved by theatrical, aesthetic beauty - it's valuable and important only while calling to that very saving beauty; and not distracting from it, not fascinating, not cheating" [4. P. 9]. The ultimate expression of the "extinction of the form" is, according to $\mathrm{S}$. Makurenkova, "the genre of musical" [16. P. 93].

Taneyev felt the tragedy's ability to awaken those inner powers that allow people to go beyond the limits of the visible world, to open the soul for the "unspeakable". V. Ivanov dreamed about such mystery play while covering the birth of the new synthetic theater, "tending to the dynamic origin" [10. P. 43]. According to Ivanov, "the divine and heroic tragedies, similar to the antique ones, and mystery plays, more or less similar to the medieval ones" [Ibid. P. 48] are the most relevant to the theater. But there is still a fundamental difference with all the drawn similarities of the reference material chosen by Taneyev and Ivanov in their creation of a special theatrical performance, retaining both mystery play and choral origin. Crucial for Ivanov's creative ideas is the image of Dionysus, emerging as a religious metaphor for creative freedom. Ivanov views in Dionysus a kind of "holy madness", "energy" and "method" of an internal experience that precedes the "prophecy" and "runs through the truly religious life". The element of the unconscious "madness" of the cult of Dionysus was alien to the Taneyev's creative idea, appealing to the tragedy in an effort to gain an equivalent of a moral imperative.

A. Scriabin conceived to create a universal "nontheatrical" event, close to the Ivanov's views. However, Scriabin, identifying his own "self" with the theurgist God, set the creation of a new art as a goal of his creativity, refusing any basis of traditions and any well-known genre models. While creating his Mystery Play, designed to carry out a grand act of the world-altering, suggests his "plot" of human history in a cosmological manner with a focus on "new mythology" (including those of H. Blavatsky). But if Scriabin's Mystery Play fed on the forces, accelerating "destructive and reviving catastrophe of the world", contributed to a radical change in the entire social system, Taneyev's trilogy on both the plot and intonational levels clearly traced the idea of transforming the world through Love. This messianic idea makes "Oresteia" kin with Rimsky-Korsakov's "The Snow Maiden" and "The Legend of the Invisible City of Kitezh". Humanity paves its way to the Light through hell and high water, being guided by the national ethical ideals, brilliantly embodied by the grandmasters of the Russian music.

Thus, despite the fact that Taneyev turns not to the Russian history or reality, his "Oresteia" appears to be the Russian version of the tragedy. Taneyev trilogy fits organically into the history of perceiving the tragedy as a genre, that started with Glinka's "A Life for the Tsar" and continued in the music dramas of Mussorgsky, Tchaikovsky, Rimsky-Korsakov and others.

\section{REFERENCES}

[1] Aranovsky, M.G. Quest for Symphony. The Problem of Genre in the Soviet Music 1960-1975. L.:Sov. Composer, 1979. 288 p.

[2] Aristotle. Poetics // The Thinkers of Greece. From Myth to Logic: Works. M.; Kharkov, 1988. P. 700-736.

[3] Asafiev, B.V. On Opera. M., 1995. 344 p.

[4] Bulgakov, S.N. Russian Tragedy // Quiet Thoughts. M. , 1996. P. 626.

[5] Belza, I.F. National Origins of Taneyev's Creativity // Taneyev and Russian Opera. M., 1946. P. 5-57.

[6] Wagner, R. Selected Works / edited, annotated, introductory and explanatory article by R.I.Gruber. M., 1935. 106 p.

[7] Wagner, R. Opera and Drama. Der Ring des Nibelungen // Selected Works. M.; SPb, 2001. 800 p.

[8] Vysheslavtsev, B.P. Ethics of Eros Transformed. M., 1994. 368 p.

[9] Hegel, G.W.F. Aesthetics: in 2 Volumes. V. II. SPb: Nauka, 2007. $604 \mathrm{p}$.

[10] Ivanov, V.I. Native and Universal. M., 1994. 428 p.

[11] Ivanov, V.I. Collected Works: 4 Volumes. Brussels, 1974. V. 2. 784 p.

[12] Korabelnikova, L.Z. S.I.Taneyev // History of Russian Music: 10 Volumes. V. 9: the End of the XIX-XX centuries. / Yu.V. Keldysh, M.P. Rahmanova, L.Z. Korabelnikova, A.M. Sokoklova. M.: Muzyka, 1994. P. 148-215.

[13] Korabelnikova, L.Z. S.I. Taneyev // Musical Encyclopedia. V. 5. M., 1981. P. 411-423.

[14] Korabelnikova, L.Z. The Works of S.I. Taneyev. M., 1986. 296 p.

[15] Kotelov, N. Trilogy and Aeschylus. Introduction // Aeschylus. Dramas. V.1 / translated by N...v. SPb., 1864. P. 1-23.

[16] Makurenkova, S.A. The Word Ontology: Apology of a Poet. The Acquisition of Atlantis. M., 2004. 320 p.

[17] Letters of P.I. Tchaikovsky and S.I.Taneyev / ed. M.I. Tchaikovsky. M.: P.Jurgenson publishing house, 1916. 188 p.

[18] Savenko, S.I. Sergei Ivanovich Taneyev. M., 1984. 174 p.

[19] Taneyev, S.I. A Moving Counterpoint of Strict Writing / ed. S.S. Bogatyrev. M. , 1959. 383 p. 
[20] Tumanina, N.V. Musical and Dramatical Concept of Taneyev's "Oristeia" Trilogy // Taneev and Russian Opera. M., 1946. P. 59-97.

[21] Yakovlev, V. S.I.Taneyev's "Oresteia" in Theater // Taneyev and Russian Opera. M., 1946. P. 99-158.

[22] Yarho, V.N. Tragedy. Ancient Greek Literature: Collected Works. M.: Labirint, 2000. 